ORIGINAL RESEARCH

\title{
Effectiveness of A Clinical Protocol Implemented To Standardize Snakebite Management In Iran: Initial Evaluation
}

\author{
Seyed Mostafa Monzavi, MD; Amir Ahmad Salarian, PharmD, PhD; Ali Reza Khoshdel, MD, PhD; \\ Bita Dadpour, MD; Reza Afshari, MD, MS, PhD \\ From the AJA University of Medical Sciences, Tehran, Iran (Drs Monzavi, Salarian, and Khoshdel); and the Addiction Research Center, Department of \\ Internal Medicine, Imam Reza Hospital, School of Medicine, Mashhad University of Medical Sciences, Mashhad, Iran (Drs Monzavi, Dadpour, and Afshari).
}

Objective.- This study was designed to evaluate the effectiveness of a new protocol implemented to standardize snakebite management in Iran.

Methods. - In this study, 27 patients treated according to the new protocol in $2012(\mathrm{P}+)$ were compared with 22 patients treated according to the previous modality in the year before implementation of the protocol (P-) in Mashhad Medical Toxicology Centre (MTC). Demographic characteristics and treatment details of all patients were recorded prospectively. Envenomation severity of each victim was assessed according to snakebite severity score (SSS).

Results.-After implementation of the protocol, a smaller percentage of patients received antivenom (AV) therapy (78\% vs $95 \% ; P=.079$ ). In spite of no significant difference in baseline severity of envenomation between the 2 groups (SSS [mean $\pm \mathrm{SD}$ ], $34.8 \pm 18.1$ vs $35.5 \pm 17.4 ; P=.801$ ), the $\mathrm{P}+$ group received significantly fewer AV vials $(8.4 \pm 6.8$ vs $12.1 \pm 5.6$ vials; $P=.042)$ and had a significantly shorter length of hospital stay $(2.2 \pm 1.5$ vs $3.2 \pm 1.8$ days; $P=.027)$. Moreover, smaller proportion of $\mathrm{P}+$ patients experienced recurrence of venom-induced effects; however, the difference was not significant $(18.5 \%$ vs $36 \% ; P=.159)$. The reduction in use of antiallergy treatments to prevent or treat acute hypersensitivity reactions approached statistical significance (41\% vs $68 \% ; P=.051)$. These findings denote a reduction in AV use of approximately 4 vials and a reduction in hospital stay of 1 day for each patient, which translates to approximately \$196/patient in healthcare cost savings.

Conclusions.- Implementation of a snakebite management protocol at MTC reduced overall antivenom usage, use of antiallergy interventions, and length of hospital stay.

Key words: antivenoms, clinical protocols, comparative effectiveness research, Iran, snakebite

\section{Introduction}

Snakebite is a toxicologic emergency that was primarily treated according to anecdotal evidences, local experiences, and empirical basis until recent decades. ${ }^{1-3}$ Thus, considerable attention has been devoted to development of unified integrated protocols for standardizing management of snakebite in different parts of the world. ${ }^{3-6}$ In Iran, a comprehensive protocol has been recently introduced that conjoined

Conflict of interest: The authors declare that they have no conflict of interest.

Corresponding author: Reza Afshari, MD, MS, PhD, Addiction Research Center, Department of Internal Medicine, Imam Reza Hospital, Mashhad University of Medical Sciences, Ibn-e-Sina Street, Mashhad 9133316791, Iran (e-mail: afsharir@mums.ac.ir, afsharireza@yahoo.com). antivenom (AV) dosage plan and recommendations for supportive treatments. ${ }^{7}$ This is the first Iranian protocol that has been designed to standardize the AV dosage and indications to overcome shortcomings of previous guidelines and to clarify indications of supportive treatments.

Annually, snakebite involves 4500 to 6500 victims in Iran, causing 3 to 9 deaths., ${ }^{2,8}$ The most prevalent medically important snakes in this country are Echis sochureki, Macrovipera lebetina obtuse, Pseudocerastes persicus persicus, and Naja oxiana: the first 3 belong to the Viperidae family, and the fourth is an Elpidae snake., ${ }^{9,10}$ The current commercially available AV in Iran (Polyvalent Snake Antivenin, Razi Serum and Vaccine Research Institute, Iran) that has been manufactured during the past 5 decades is capable of counteracting the venoms of these snakes. ${ }^{11}$ 
Mashhad Medical Toxicology Centre (MTC) in Imam Reza Hospital is a referral medical toxicology department in northeast Iran that admits 25 to 60 snakebite victims each year with less than $1 \%$ mortality rate. ${ }^{2}$ Snakebite events in this part of the country mostly occur during April to late October. ${ }^{12}$ During the past 3 decades, a local treatment modality for snakebites mainly designed according to western references has been practiced in MTC. ${ }^{2,8}$ Although the treatment modality has been effective in terms of saving many lives, its cost-benefit has remained obscure. Moreover, its effectiveness has been affected by differing interpretations of the grading of envenomation severity, undefined therapeutic response (or initial control), and unspecified indications for supportive treatments. ${ }^{7}$ Hence, through elaborating the modality, rectifying its defects, and enhancing neglected aspects, an integrated protocol has been developed in MTC by a focus group of medical toxicologists and expert physicians in other areas of medicine. ${ }^{7}$ The new protocol includes: 1) a grading scale that enabled a more objective assessment of victims (snakebite envenomation severity scale, SESS); 2) an algorithm consisting of planned course of action and AV dosing (Figure); and 3) a table of instructions for supportive treatments.

The aim of this study was to evaluate the effectiveness of the new protocol according to the overall $\mathrm{AV}$ volume administered to patients, morbidities, and duration of admission after its institution in 2012.

\section{Methods}

\section{DESIGN AND SETTING}

This was a prospective comparative study of snakebite victims admitted to MTC during 2011 and 2012. The study was started prospectively in 2011 with precise data collection of patients who were treated according to previous modality and continued with careful observation of the patients treated according to the new protocol in 2012.

\section{PATIENTS}

The patients treated according to the new protocol between April 1, 2012, and October 30, 2012 (P+), were compared with patients who received treatment according to the previous modality in the same period of the year before implementation of the protocol $(\mathrm{P}-)$. Demographic characteristics and clinical manifestations of all patients as well as treatment details were recorded in a predesigned checklist by 2 of us (S.M.M. and B.D.). At presentation, the envenomation severity of each victim was also assessed by these researchers according to the snakebite severity score (SSS). ${ }^{13}$

\section{TREATMENTS}

To start attacking the venom and promptly reversing the venom effects, a specified amount of the AV called the attack dose (or initial dose in other internationally recognized protocols) should be given to the patient at a relatively rapid rate. The attack dose may be repeated according to the patient's condition (subsequent attack dose). For maintaining a steady AV level in the blood to prevent venom-AV mismatch and recurrence of venom effects, the maintenance dose of AV should be infused at a slow rate. Differences between the 2 treatment plans rely on the definition of these doses, the rate of $\mathrm{AV}$ administration, the time to repeat antivenom, indication of supportive treatments, etc. The characteristics of the new protocol and the previous modality are summarized in Table 1. As shown, in the new protocol compared with the previous treatment modality: $:^{7,8}$

1. The grading system (SESS) has been defined with more details and has been simplified into 3 grades.

2. The extent of $<2.5 \mathrm{~cm}$ has been defined as the threshold of edema that does not need to be treated. However, for bites on digits, any level of edema has been determined as an indication for $\mathrm{AV}$ administration.

3. The systemic venom effects have been clarified with more detailed definitions in the grading scale.

4. The highest AV volume at each attack dose has been limited to 10 vials, half of the amount recommended in the previous treatment modality.

5. The infusion rate of the attack dose has been increased.

6. Therapeutic response has been defined and its assessment has become mandatory.

7. Administration of subsequent attack doses depended on the failure to achieve the therapeutic response.

8. The maintenance dose and the dose for recurrence of venom-induced effects have been fixed at 5 vials.

9. The maximum of total attack doses (upper limit of AV attack dosage) has been set at 20 vials except for uncontrollable bleeding and critically ill patients.

10. The skin test has been discontinued.

11. Pretreatment for immediate allergic reactions (IARs) has been limited to severe atopic syndrome and previous sensitization to biological products.

12. The time to discharge has been defined as 18 hours after admission after 4 normal 20-minute wholeblood clotting tests (20-minute WBCT) for minimal cases and 24 hours after stabilization of severe and very severe cases. 


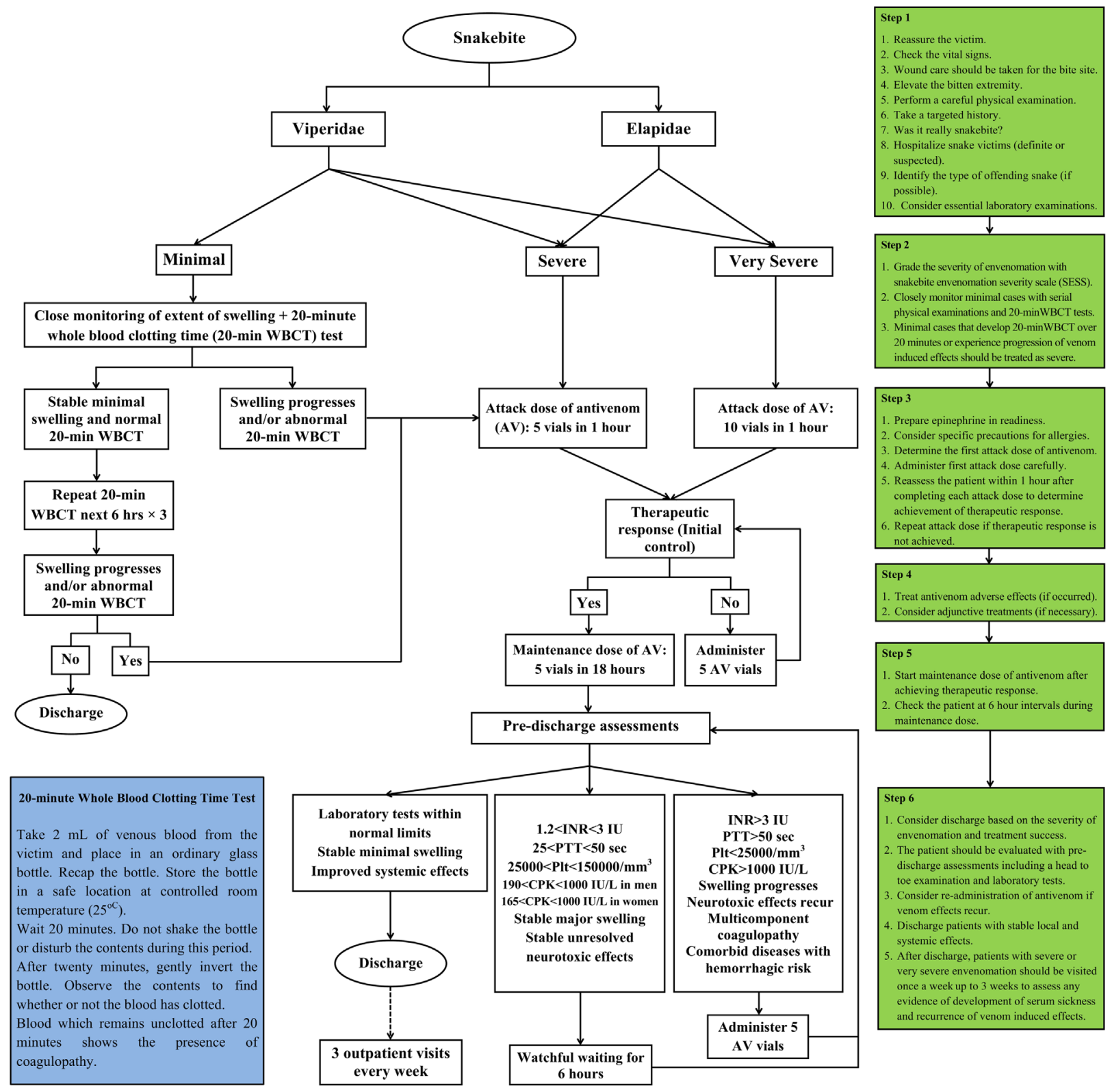

Figure. Algorithm for management of snakebite envenomation in the new protocol (adapted from Monzavi et al ${ }^{7}$ with permission). AV, antivenom; CPK, creatine phosphokinase; INR, international normalized ratio; Plt, platelet count; PTT, partial thromboplastin time; SESS, snakebite envenomation severity scale; WBCT, whole-blood clotting test.

\section{ETHICS}

The study was approved by the ethics committee of the Mashhad University of Medical Sciences. The protocol was designed according to previous regional studies, local experience, and internationally recognized textbooks, and if controversy existed, the focus group selected the most appropriate and conservative treatment. With a feedback from the focus group, the new protocol was implemented in MTC based on a staffing decision. All patients received meticulous care under the supervision of the researchers. It had also been planned to stop AV administration if the patient showed any sign of IARs.

\section{STATISTICAL ANALYSIS}

To compare the means of normally distributed dependent variables between $\mathrm{P}+$ and $\mathrm{P}-$ patients, we performed independent samples Student's $t$ tests, and for nonnormally distributed dependent variables, the MannWhitney $U$ test was used. For comparing proportions 
Table 1. Comparison of the new protocol with the previous treatment modality

\begin{tabular}{|c|c|c|}
\hline Item & Previous treatment modality & New protocol \\
\hline Grading & 4 grades & 3 grades \\
\hline Minimal & $\begin{array}{l}\text { Fang marks, without pain and } \\
\text { swelling, no systemic manifestation }\end{array}$ & $\begin{array}{l}\text { Local swelling (erythema or } \\
\text { ecchymosis) }<2.5 \mathrm{~cm} \text { around the fang } \\
\text { marks, tolerable pain, mild discomfort, } \\
\text { no systemic manifestation }\end{array}$ \\
\hline Moderate & $\begin{array}{l}\text { Fang marks, swelling from bite site to } \\
\text { adjacent joint, no systemic } \\
\text { manifestation }\end{array}$ & Not included \\
\hline Severe & $\begin{array}{l}\text { Fang marks, swelling involving entire } \\
\text { bitten limb, blister/bulla formation, no } \\
\text { systemic manifestation }\end{array}$ & $\begin{array}{l}\text { Any swelling in digits, swelling } \\
\text { (erythema or ecchymosis) }>2.5 \mathrm{~cm} \\
\text { around the fang marks, rapidly } \\
\text { progressive swelling, marked pain, } \\
\text { local tissue destruction (dermal or } \\
\text { muscle necrosis), bulla and blister } \\
\text { formation, bites in the head and neck } \\
\text { region, regional lymphadenitis, } \\
\text { uncontrollable vomiting, generalized } \\
\text { weakness, spontaneous bleeding, } \\
\text { cardiac dysrhythmia or abnormal ECG, } \\
\text { increased creatinine, } \\
\text { thrombocytopenia, increased } \\
\text { coagulation tests (INR }>1.2, \text { PT }>20 \\
\text { s, PTT > }>50 \mathrm{~s} \text { ) }\end{array}$ \\
\hline Very severe & $\begin{array}{l}\text { Swelling beyond the bitten limb, } \\
\text { extensive local necrosis, compartment } \\
\text { syndrome, any systemic manifestation }\end{array}$ & $\begin{array}{l}\text { Bites in the head and neck region with } \\
\text { possibility of upper airway obstruction, } \\
\text { compartment syndrome, cardiovascular } \\
\text { collapse (cardiac arrest, overt shock } \\
\text { [SBP }<80 \mathrm{~mm} \mathrm{Hg} \text { and reduced } \\
\text { peripheral perfusion]), } \\
\text { rhabdomyolysis, severe active bleeding }\end{array}$ \\
\hline Each attack (initial) dose & $\begin{array}{l}\text { Minimal envenomation: no antivenom } \\
\text { Moderate: } 2-4 \text { vials } \\
\text { Severe: } 5-9 \text { vials } \\
\text { Very severe: } 10-20 \text { vials }\end{array}$ & $\begin{array}{l}\text { Minimal envenomation: no antivenom } \\
\text { Severe: } 5 \text { vials } \\
\text { Very severe: } 10 \text { vials (first dose only) } \\
\text { with subsequent doses of } 5 \text { vials (if } \\
\text { needed) }\end{array}$ \\
\hline 20-minute WBCT & Not recommended & $\begin{array}{l}\text { Serial checking of } 20 \text {-minute WBCT } \\
\text { every } 6 \text { hours for patients with } \\
\text { minimal severity up to } 4 \text { times. Any } \\
\text { abnormal } 20 \text {-minute WBCT is an } \\
\text { indication for antivenom } \\
\text { administration. }\end{array}$ \\
\hline Maximum of total attack doses & Not defined & $\begin{array}{l}20 \text { vials except uncontrollable bleeding } \\
\text { and critically ill patients }\end{array}$ \\
\hline Infusion rate of attack dose & $\begin{array}{l}\text { Half in } 1 \text { hour and half in next } 12-48 \\
\text { hours }\end{array}$ & Whole dose in 1 hour \\
\hline Definition of therapeutic response & Not clearly defined and assessed & $\begin{array}{l}\text { Arrest of swelling progression or other } \\
\text { local manifestations, improvement in } \\
\text { coagulation tests, platelet count, and } \\
\text { other systemic manifestations }\end{array}$ \\
\hline Maintenance dose & Half of the attack dose in $12-24$ hours & $\begin{array}{l}5 \text { vials in } 18 \text { hours (only for severe and } \\
\text { very severe cases) }\end{array}$ \\
\hline Recurrence & $\begin{array}{l}\text { Readministration of antivenom with } \\
\text { half of the attack dose }\end{array}$ & $\begin{array}{l}\text { Readministration of } 5 \text { vials of } \\
\text { antivenom. No maintenance dose is } \\
\text { needed. }\end{array}$ \\
\hline
\end{tabular}


Table 1 (continued)

\begin{tabular}{|c|c|c|}
\hline Item & Previous treatment modality & New protocol \\
\hline Preantivenom administration care & $\begin{array}{l}\text { Skin test: mandatory } \\
\text { Epinephrine drawn up in readiness } \\
\text { Intravenous chlorpheniramine and } \\
\text { hydrocortisone: recommended for all } \\
\text { patients }\end{array}$ & $\begin{array}{l}\text { Skin test: not recommended } \\
\text { Epinephrine drawn up in readiness } \\
\text { Intravenous chlorpheniramine and } \\
\text { hydrocortisone: indicated for severely } \\
\text { atopic patients and those previously } \\
\text { sensitized to biological products }\end{array}$ \\
\hline Time to discharge & Not defined & $\begin{array}{l}\text { After } 4 \text { normal } 20 \text {-minute WBCTs } \\
\text { within } 18 \text { hours after admission for } \\
\text { minimal cases, } 24 \text { hours after } \\
\text { therapeutic response with stable } \\
\text { minimal swelling, laboratory results } \\
\text { within normal limits, and clinical } \\
\text { improvement of systemic } \\
\text { manifestations for severe and very } \\
\text { severe cases }\end{array}$ \\
\hline
\end{tabular}

ECG, electrocardiograph; INR, international normalized ratio; PT, prothrombin time; PTT, partial thromboplastin time; SBP, systolic blood pressure; WBCT, whole-blood clotting test.

between the 2 groups, the $\chi^{2}$ test was used. Analyses were done using SPSS for Windows (SPSS Inc, Chicago, IL). Probability values of less than .05 were considered statistically significant.

\section{Results}

\section{EPIDEMIOLOGICAL PROFILE OF SNAKEBITE PATIENTS IN BOTH YEARS}

Forty-nine victims $(65 \%$ men) were enrolled during the 2 -year period of the study. Most of the victims (39\%) were young adults (20-39 years old). The majority of bites $(90 \%)$ occurred in rural areas (Table 2). Echis sochureki was responsible for most bites (39\%), followed by Macrovipera lebetina obtuse (16\%). The identity of offending snakes in the remaining cases could not be established $(45 \%)$. In the greater number of events, upper extremities $(51 \%)$ were affected followed by lower extremities (45\%). No or fewer than $10 \mathrm{AV}$ vials in total were administered for a higher proportion of patients (61\%). Most of the patients were discharged in less than 3 days of hospital stay (75\%). None of the patients required intensive care unit admission, and no deaths occurred.

\section{ANALYSIS OF EFFECTIVENESS}

Twenty-two patients were treated according to the previous modality $(\mathrm{P}-)$ and 27 patients after implementation of the new protocol $(\mathrm{P}+)$. The 2 groups showed no significant difference in age $(P=.894)$ and sex distribution $(P=.703)$. No significant difference in the extent of edema $(P=.085)$, frequency of bites on digits $(P=.449)$, and the development of coagulopathy $(P=$ .336) was noted between the 2 groups (Table 3 ). In addition, in both years, no posttreatment complications including renal failure, bleeding complications, and neurologic sequelae were seen except a case with dermal necrosis that was treated with previous modality.

Pretreatment for IARs (administration of corticosteroids or chlorpheniramine before AV therapy) was significantly reduced by adherence to the new protocol (33\% vs $64 \% ; P=.035$ ). Nevertheless, the occurrence of IARs was not significantly different between the 2 groups $(P=.678)$. Moreover, the reduction in overall anti-IAR care delivered to the patients (either as pretreatment or treatment) approached statistical significance ( $41 \%$ vs $68 \% ; P=.051)$.

After implementation of the protocol, a smaller percentage of patients received AV therapy, although the difference was only close to statistical significance (78\% vs $95 \% ; P=.079$ ). In spite of no significant difference in baseline severity of envenomation between the 2 groups (SSS [mean \pm SD], $34.8 \pm 18.1$ vs $35.5 \pm$ $17.4 ; P=.894)$, the $\mathrm{P}+$ group received significantly fewer AV vials $(8.4 \pm 6.8$ vs $12.1 \pm 5.6$ vials; $P=.042)$ and had a significantly shorter length of hospital stay $(2.2 \pm 1.5$ vs $3.2 \pm 1.8$ days; $P=.027)$. In addition, smaller proportion of $\mathrm{P}+$ patients experienced recurrence of venom-induced effects; however, the difference was not significant $(18.5 \%$ vs $36 \% ; P=.159)$.

These findings denote approximately 4 vials reduction in AV use and 1 day reduction in hospital stay for each 
Table 2. Demographic features of patients, circumstances of the bites, treatments, and outcomes $(n=49)$

\begin{tabular}{|c|c|}
\hline Variable & $N(\%)$ \\
\hline \multicolumn{2}{|l|}{ Sex } \\
\hline Male & $32(65)$ \\
\hline Female & $17(35)$ \\
\hline \multicolumn{2}{|l|}{ Age group (years) } \\
\hline$\leq 11$ & $3(6)$ \\
\hline $12-19$ & $9(18)$ \\
\hline $20-39$ & $19(39)$ \\
\hline$\geq 40$ & $18(37)$ \\
\hline \multicolumn{2}{|l|}{ Location of event } \\
\hline Rural & $44(90)$ \\
\hline Urban & $5(10)$ \\
\hline \multicolumn{2}{|l|}{ Offending snake species } \\
\hline Echis sochureki & $19(39)$ \\
\hline Macrovipera lebetina obtuse & $8(16)$ \\
\hline Uncertain & $22(45)$ \\
\hline \multicolumn{2}{|l|}{ Anatomical location of bite } \\
\hline Upper extremity & $25(51)$ \\
\hline Lower extremity & $22(45)$ \\
\hline Head and neck & $2(4)$ \\
\hline \multicolumn{2}{|l|}{ Total antivenom treatment (vials) ${ }^{a}$} \\
\hline None & $7(14)$ \\
\hline $1-5$ & $8(16)$ \\
\hline $6-10$ & $15(31)$ \\
\hline $11-15$ & $14(29)$ \\
\hline$\geq 16$ vials & $5(10)$ \\
\hline \multicolumn{2}{|l|}{ Duration of admission (days) } \\
\hline$\leq 1$ & $13(26)$ \\
\hline 2 & $17(35)$ \\
\hline 3 & $7(14)$ \\
\hline$\geq 4$ & $12(25)$ \\
\hline ICU admission & $0(0)$ \\
\hline Death & $0(0)$ \\
\hline
\end{tabular}

${ }^{a}$ Attack dose + maintenance dose.

ICU, intensive care unit.

patient. As the production cost of each AV vial (Razi antivenin) is \$28 US and charges for 1-day stay in public hospitals are about $\$ 84$ US in Iran, ${ }^{14}$ the implementation of the protocol resulted in approximately $\$ 196$ US/patient savings in healthcare cost.

\section{Discussion}

Snakebite as a medical toxicologic emergency has often been associated with excessive fears and concerns for both the patient and the treating physician. In the past, some physicians were inclined to administer high doses of AV for all victims to not miss any seemingly minimal case with underlying severe envenomation. In addition, in some old-fashioned treatment modalities and guidelines that were generally based on unreliable subjective experiences and evidences from countries with higher incomes or more dangerous snakes, high doses of AV have been recommended. Moreover, in some developing countries, the cost of manufacturing and distribution of AV products have been covered by the governments. These have resulted in overtreatment of the victims and waste of medical resources. ${ }^{6,8,15,16}$ In this study, we showed that implementation of an updated evidencebased protocol can reduce unnecessary treatments, morbidities, and overall healthcare costs.

The epidemiological profile of patients in the present study generally resembles the previous reports from Iran and other countries. ${ }^{6,8,12,15,17-20}$ Snakebite mostly affects a young male population. ${ }^{12,17-20}$ It is an environmental threat especially in rural areas..$^{12,18,21}$ The extremities are the most affected parts of the body. ${ }^{6,8,12,15,17-20}$ However, in some studies including the present one, the upper extremities were more involved compared with the lower extremities. ${ }^{8,12,17,18}$ Conversely, in reports from India, Bangladesh, and Afghanistan, the lower extremities were mostly affected. ${ }^{6,19,20}$ This discrepancy is probably related to clothing cultures in these countries, as in the Indian subcontinent, the lower extremities are less covered with clothes and are easily exposed to bites. In this study, Echis sochureki was the most common offending snake among identifiable cases. Echis sochureki is highly distributed and is responsible for most snake attacks to humans in the region. ${ }^{2,9,10,15,18}$ To reverse the effects of its venom, Razi Antivenin has shown to be a potent product. ${ }^{7,8,11,18}$ It is a $\mathrm{F}\left(\mathrm{ab}^{\prime}\right)_{2}$ polyvalent $\mathrm{AV}$ derived from equine serum through a costly manufacturing process. ${ }^{11}$ Hence, it is potentially a hypersensitivity-inducing agent, especially in high volumes. $^{21}$ These facts emphasize the necessity of rationalizing the $\mathrm{AV}$ usage and maximizing healthcare resources. In recent years, great efforts have been focused on developing national protocols for snakebite management in different countries to achieve these goals. ${ }^{4-7}$

In the United States, Crotalidae Polyvalent Immune Fab (CroFab) has replaced the Wyeth Antivenin (Crotalidae) Polyvalent (ACP) since 2000. ${ }^{22}$ Premarketing studies recommended 4 to 6 vials as the initial dose. ${ }^{23}$ In a postmarketing study by Dart et al, ${ }^{22} 6$ vials (2 vials every 6 hours) were recommended as the maintenance dose to prevent recurrence of venominduced effects. In light of these studies, Weant et $\mathrm{al}^{4}$ proposed a multiaspect protocol to ensure appropriate patient evaluation, CroFab use, and follow-up in 2010. The protocol led to a decrease of 2.2 vials in AV use and 0.8 day shorter hospital stay, which meant $\$ 2000$ US/ patient healthcare cost savings. ${ }^{24}$ Lavonas et $\mathrm{al}^{5}$ 
Table 3. Comparative analysis of patients treated with the new protocol and previous modality

\begin{tabular}{|c|c|c|c|}
\hline Factor & Previous modality $(n=22)$ & New protocol $(n=27)$ & $P$ value \\
\hline Male sex, n (\%) & $15(68)$ & $17(63)$ & .703 \\
\hline Age (year), mean $\pm \mathrm{SD}$ & $35.5 \pm 17.4$ & $34.8 \pm 18.1$ & .894 \\
\hline Snakebite severity score, mean $\pm \mathrm{SD}$ & $3.5 \pm 1.8$ & $3.3 \pm 1.6$ & .801 \\
\hline Edema $<2.5 \mathrm{~cm}, \mathrm{n}(\%)$ & $11(50)$ & $7(26)$ & .085 \\
\hline Coagulopathy, $\mathrm{n}(\%)^{a}$ & $12(54)$ & $11(41)$ & .336 \\
\hline Bites on digits, $\mathrm{n}(\%)$ & $7(32)$ & $6(22)$ & .449 \\
\hline AV therapy, n (\%) & $21(95)$ & $21(78)$ & .079 \\
\hline $\mathrm{AV}$ (vials), mean $\pm \mathrm{SD}$ & $12.1 \pm 5.6$ & $8.4 \pm 6.8$ & .042 \\
\hline Recurrence, $\mathrm{n}(\%)^{b}$ & $8(36)$ & $5(19)$ & .159 \\
\hline IARs, n (\%) & $1(4)$ & $2(7)$ & .678 \\
\hline Pretreatment for IARs, n (\%) & $14(64)$ & $9(33)$ & .035 \\
\hline Anti-IARs care, $\mathrm{n}(\%)^{c}$ & $15(68)$ & $11(41)$ & .051 \\
\hline Length of hospital stay (days), mean $\pm \mathrm{SD}$ & $3.2 \pm 1.8$ & $2.2 \pm 1.5$ & .027 \\
\hline
\end{tabular}

\footnotetext{
${ }^{a}$ Thrombocytopenia and/or increased coagulation tests.

${ }^{b}$ Remanifestation of venom effects after achievement of therapeutic response.

${ }^{c}$ Administration of corticosteroid/chlorpheniramine ( \pm epinephrine) either as pretreatment or treatment for allergic reactions.

$\mathrm{AV}$, antivenom; IARs, immediate allergic reactions.
}

reassessed and augmented the protocol with other practical aspects in 2011.

In India also, many efforts have been made toward a rational AV usage. In 1999, Tariang et $\mathrm{al}^{25}$ proposed a low-dose AV regimen instead of a high-dose conventional regimen. They showed a savings of $5 \mathrm{AV}$ vials (1000 rupees or \$23 US per patient) with no difference in morbidities and mortalities by applying their new dose regimen. In 2004, Srimannarayana et $\mathrm{al}^{26}$ also showed that lower-dose AV regimens compared with conventional regimens can significantly reduce AV use and recurrence of venom effects with similar mortalities. Considering this information, Ghosh et $\mathrm{al}^{6,27}$ reassessed available guidelines and devised a clinical protocol for standardizing snakebite management in West Bengal in 2008. Their protocol resulted in a $66 \%$ reduction in AV use, equivalent to $\$ 150,000$ US annual cost saving, and a $24 \%$ reduction in mortality rate.

In Iran, it was shown that 5 vials of $\mathrm{AV}$ as an attack dose is effective and adequate to control venom effects in most cases. ${ }^{8,28}$ Nevertheless, in the previous accepted modality, very high volumes of AV was proposed. ${ }^{2,8}$ Therefore, the new protocol has been devised to reduce variations in practice and normalize AV usage. ${ }^{7}$ In the present study, we showed that the protocol can lower the AV use and duration of admission. These have been achieved with clear definitions of AV therapy indications and end points, the indications of repeating $\mathrm{AV}$, uniform attack and maintenance $\mathrm{AV}$ doses, and applicable severity grading scale. According to the new protocol, patients without systemic manifestations and less than $2.5 \mathrm{~cm}$ of local edema will be graded as having minimal severity of envenomation and will not receive $\mathrm{AV}{ }^{7}$ Instead, they will receive 18 hours of close observation, and within this time frame their coagulation status will be checked with a 20-minute WBCT every 6 hours. The value of the 20-minute WBCT to guide the successful management of systemic envenomation has been ascertained in earlier studies. ${ }^{29,30}$ When compared with prior practice in which any minor edema was an indication for $\mathrm{AV}$, the new protocol limits administration to victims with more than $2.5 \mathrm{~cm}$ of swelling or systemic findings. Nevertheless, in the new protocol, any level of edema on digits is still an indication for AV administration similar to the previous modality. ${ }^{2,7}$ Also, in the World Health Organization guideline for the management of snakebites, AV therapy has been recommended for any swelling after bites on the digits (toes and especially fingers). ${ }^{31}$ The reason for this exception is that the subtissue compartments of the digits are surrounded with limited space and tight fascial membranes, and subsequent to a swelling, the elastic limit of the skin can be rapidly reached and so the possibility of tissue necrosis and compartment syndrome is higher. ${ }^{32,33}$

Furthermore, the new protocol delineated the time to discharge to be after 4 normal 20-minute WBCTs within 18 hours after admission for minimal cases and 24 hours after therapeutic response for severe and very severe cases. ${ }^{7}$ These new ceilings also reduced the length of hospital stay. Overall, the reduction in hospital stay and AV use was equivalent to \$196 US per each Iranian patient. Considering that a brain magnetic resonance imaging study costs about $\$ 60$ US in $\operatorname{Iran}^{14}$ and $\$ 424$ US in the United States (approximately 7 times that in 
Iran) ${ }^{34}$ the cost saving resulting by application of the new protocol can be equal to $\$ 1372 \mathrm{US} /$ patient in the United States.

In addition, with the new protocol, the rate of recurrence of venom effects diminished. This is probably caused by addition of a fixed 5-vial maintenance dose to the new protocol, which is able to prevent redistribution of deposited venom to the blood circulation after clearance of the attack dose of AV. ${ }^{35}$ Moreover, the use of antiallergy medications was standardized by using the protocol. The development of IARs after AV therapy is reported to be very low. ${ }^{1,5,8,21}$ On the other hand, most IARs, when they occur, are minor and satisfactorily responsive to antiallergic treatments. ${ }^{1,5,21}$ Hence, pretreatment for hypersensitivity reactions is controversial and not advocated in most approaches. ${ }^{1,4-7,21}$ Ghosh et $\mathrm{al},{ }^{6}$ Weant et $\mathrm{al}^{4}{ }^{4}$ and Lavonas et $\mathrm{al}^{5}$ also abandoned anti-IAR pretreatment in their protocols.

Excessive use of biologic products predisposes patients to acute and late-onset hypersensitivity reactions. Shortages in national and regional medical stockpiles attributable to ceased or decreased production and inadequate distribution are a potential dilemma in both high- and low-income countries. ${ }^{36,37}$ Thus, it is necessary to use medical resources more wisely and to keep hospital beds available for patients with more serious conditions. Local and national evidence-based protocols are key elements to minimize both risks and medical resource wastage.

\section{LIMITATIONS}

There are some limitations to this study. The relatively small sample size of the study may expose the findings of the study to type II errors. Further prospective studies with larger sample sizes may refine the statistical significance of the study. Another limitation of the study was that the development of serum sickness could not be compared between the groups. This is because of the fact that although the patients were asked to come to outpatient clinics for 3 follow-up visits during the first 3 weeks after discharge, ${ }^{7}$ the vast majority of them did not adhere and came after more than a month (range, 1-4 months). Despite our ability during the visits after a month to evaluate renal function by measurement of serum creatinine, hematologic status by complete blood count, and neurologic condition by neurologic examinations, the development of serum sickness, which is most probable in the first 3 weeks after AV therapy, ${ }^{3,7}$ could not be precisely assessed. However, we can assume that when a patient did not complain or give a history of specific signs of serum sickness (such as skin rashes, fever, itching, lymphadenitis, and arthralgia) during the mentioned time, they were either absent or too minor to be noted.

Moreover, the results presented in this study were obtained from a center in northeast Iran and may not be able to show the exact picture of the effectiveness of the protocol and the snakebite epidemiology in all parts of the country. After introduction of the protocol and its utilization in a single referral medical toxicology center, the next phase will be training the protocol to other national centers and evaluating its effectiveness on a larger scale.

\section{Conclusions}

A standardized protocol can reduce major variations in snakebite management, diminish unnecessary AV administration, and reduce healthcare costs. The designing of a region-specific multidisciplinary protocol based on medical capacity and infrastructure of each country may be cost-beneficial and is recommended.

\section{Acknowledgments}

We would like to thank Dr B. Dormanesh, AJA University of Medical Sciences, for her kind support. We also acknowledge Mr S. M. Ziaie and the staff of Mashhad Medical Toxicology Centre for their unstinting assistance during this study.

\section{References}

1. Warrell DA. Snake bite. Lancet. 2010;375:77-88.

2. Afshari R, Monzavi SM. Venomous animals and arthropods envenomation [in Persian]. In: Afshari R, Monzavi SM, eds. Afshari's Clinical Toxicology and Poisoning Emergency Care. 2nd ed. Mashhad, Iran: Mashhad University of Medical Sciences Publication; 2012:221-241.

3. Pizon AF, Riley BD, Ruha AM. Antidotes in depth: antivenom (Crotaline). In: Nelson LS, Lewin NA, Howland MA, Hoffman RS, Goldfrank LR, Flomenbaum NE, eds. Goldfrank's Toxicologic Emergencies. 9th ed. New York, NY: McGraw-Hill; 2011:1611-1614.

4. Weant KA, Johnson PN, Bowers RC, Armitstead JA. Evidence-based multidisciplinary approach to the development of a crotalidae polyvalent antivenin (CroFab) protocol at a university hospital. Ann Pharmacother. 2010;44: 447-455.

5. Lavonas EJ, Ruha AM, Banner W, et al. Unified treatment algorithm for the management of crotaline snakebite in the United States: results of an evidence-informed consensus workshop. BMC Emerg Med. 2011;11:2.

6. Ghosh S, Maisnam I, Murmu BK, Mitra PK, Roy A, Simpson ID. A locally developed snakebite management protocol significantly reduces overall anti snake venom utilization in West Bengal, India. Wilderness Environ Med. 2008;19:267-274. 
7. Monzavi SM, Dadpour B, Afshari R. Snakebite management in Iran: devising a protocol. J Res Med Sci. 2014;19: 153-163.

8. Dadpour B, Shafahi A, Monzavi SM, Zavar A, Afshari R, Khoshdel AR. Snakebite prognostic factors: leading factors of weak therapeutic response following snakebite envenomation. Asia Pac J Med Toxicol. 2012;1:27-33.

9. Firouz E. The Complete Fauna of Iran. London, England: I.B. Tauris; 2005.

10. Latifi M. Snakes of Iran [in Persian]. Tehran: Publication of Iran Department of Environment; 1991.

11. Theakston RD, Warrell DA. Antivenoms: a list of hyperimmune sera currently available for the treatment of envenoming by bites and stings. Toxicon. 1991;29:14191470 .

12. Dehghani R, Rabani D, Panje Shahi M, Jazayeri M, Sabahi Bidgoli M. Incidence of snake bite in Kashan, Iran during an eight year period (2004-2011). Arch Trauma Res. 2012;1:67-71.

13. Dart RC, Hurlbut KM, Garcia R, Boren J. Validation of a severity score for the assessment of crotalid snakebite. Ann Emerg Med. 1996;27:321-326.

14. Shokoohizadeh M, Liaghat AR, Marashi H, Mihandoust A, Attaran AR. The cost and length of a stay in different hospital departments: an analytical study in Iran [in Persian]. J Mashhad Med Counc. 2013;17:81-84. Available from: http://jmmc.mums.ac.ir/article_2289_342.html. Accessed November 21, 2014.

15. Mahmood K, Naqvi IH, Talib A, et al. Clinical course and outcome of snake envenomation at a hospital in Karachi. Singapore Med J. 2010;51:300-305.

16. Theakston RD, Warrell DA, Griffiths E. Report of a WHO workshop on the standardization and control of antivenoms. Toxicon. 2003;41:541-557.

17. Sagheb MM, Sharifian M, Moini M, Salehi O. Clinical features of snake bite in southern Iran. Trop Doct. 2011;41:236-237.

18. O’Neil ME, Mack KA, Gilchrist J, Wozniak EJ. Snakebite injuries treated in United States emergency departments, 2001-2004. Wilderness Environ Med. 2007;18:281-287.

19. Heiner JD, Bebarta VS, Varney SM, Bothwell JD, Cronin AJ. Clinical effects and antivenom use for snake bite victims treated at three US hospitals in Afghanistan. Wilderness Environ Med. 2013;24:412-416.

20. Mondal RN, Chowdhury FR, Rani M, et al. Pre-hospital and hospital management practices and circumstances behind venomous snakebite in northwestern part of Bangladesh. Asia Pac J Med Toxicol. 2012;1:18-21.

21. Lalloo DG, Theakston RD. Snake antivenoms. J Toxicol Clin Toxicol. 2003;41:277-290, 317-327.

22. Dart RC, Seifert SA, Boyer LV, et al. A randomized multicenter trial of crotalinae polyvalent immune Fab (ovine) antivenom for the treatment for crotaline snakebite in the United States. Arch Intern Med. 2001;161:20302036.
23. Dart RC, McNally J. Efficacy, safety, and use of snake antivenoms in the United States. Ann Emerg Med. 2001; 37:181-188.

24. Weant KA, Bowers RC, Reed J, Braun KA, Dodd DM, Baker SN. Safety and cost-effectiveness of a clinical protocol implemented to standardize the use of Crotalidae polyvalent immune Fab antivenom at an academic medical center. Pharmacotherapy. 2012;32:433-440.

25. Tariang DD, Philip PJ, Alexander G, et al. Randomized controlled trial on the effective dose of anti-snake venom in cases of snake bite with systemic envenomation. $J$ Assoc Physicians India. 1999;47:369-371.

26. Srimannarayana J, Dutta TK, Sahai A, Badrinath S. Rational use of anti-snake venom (ASV): trial of various regimens in hemotoxic snake envenomation. J Assoc Physicians India. 2004;52:788-793.

27. Ghosh S. Management of snake bite-an update. In: Bichile SK, Hase NK, Mehta SS, eds. Medicine Update. 18th ed. Mumbai, India: The Association of Physicians of India; 2008:691-696.

28. Mostaghni AA, Alipour MB. Abnormalities in coagulation profile in snake-bite, Bushehr Province/Iran [in Persian]. Iranian South Med J. 1998;1:79-88.

29. Gaus DP, Herrera DF, Troya CJ, Guevara AH. Management of snakebite and systemic envenomation in rural Ecuador using the 20-minute whole blood clotting test. Wilderness Environ Med. 2013;24:345-350.

30. White J. Snake venoms and coagulopathy. Toxicon. 2005;45:951-967.

31. Warrell DA. Guidelines for the Management of SnakeBites. 2nd ed. New Delhi, India: WHO Press; 2010.

32. Lykissas MG, Koulouvaris P, Kostas-Agnantis I, Gkiatas I, Milionis HJ, Mavrodontidis AN. Snakebites of fingers or toes by viperidae family members: an orthopaedic approach. Acta Orthop Belg. 2011;77:246-251.

33. Bozkurt M, Kulahci Y, Zor F, Kapi E. The management of pit viper envenomation of the hand. Hand (NY). 2008;3: 324-331.

34. Stokes M, Becker WJ, Lipton RB, et al. Cost of health care among patients with chronic and episodic migraine in Canada and the USA: results from the International Burden of Migraine Study (IBMS). Headache. 2011;51: 1058-1077.

35. Boyer LV, Seifert SA, Cain JS. Recurrence phenomena after immunoglobulin therapy for snake envenomations: Part 2. Guidelines for clinical management with crotaline Fab antivenom. Ann Emerg Med. 2001;37:196-201.

36. Simpson ID. The "worldwide shortage" of antisnake venom: is the only right answer "produce more" or is it also "use it smarter?." Wilderness Environ Med. 2008;19: 99-107.

37. Gorodetsky RM, Hon SL, Geller RJ, Morgan BW. The beneficial auxiliary role of poison information centers: stewardly use of rabies post-exposure prophylaxis in a time of shortage. Asia Pac J Med Toxicol. 2012;1:34-37. 